\title{
RESEARCH
}

Open Access

\section{The effects of cerebrospinal fluid tap-test on idiopathic normal pressure hydrocephalus: an inertial sensors based assessment}

\author{
Alberto Ferrari ${ }^{1 *}$ (D), David Milletti ${ }^{2}$, Giulia Giannini ${ }^{3,4}$, Sabina Cevoli ${ }^{3}$, Federico Oppi ${ }^{3}$, Giorgio Palandri ${ }^{5}$, \\ Luca Albini-Riccioli ${ }^{6}$, Paolo Mantovani ${ }^{5}$, Laura Anderlucci ${ }^{7}$, Pietro Cortelli ${ }^{3,4}$ and Lorenzo Chiari ${ }^{1,8}$
}

\begin{abstract}
Background: Gait disturbances are typical of persons with idiopathic normal pressure hydrocephalus (iNPH) without signs distinctive from other neurodegenerative and vascular conditions. Cerebrospinal fluid tap-test (CSF-TT) is expected to improve the motor performance of iNPH patients and is a prognostic indicator in their surgical management. This observational prospective study aims to determine which spatio-temporal gait parameter(s), measured during instrumented motor tests, and clinical scale(s) may provide a relevant contribution in the evaluation of motor performance pre vs. post CSF-TT on iNPH patients with and without important vascular encephalopathy.

Methods: Seventy-six patients (20 with an associated vascular encephalopathy) were assessed before, and 24 and $72 \mathrm{~h}$ after the CSF-TT by a timed up and go test (TUG) and an $18 \mathrm{~m}$ walking test $(18 \mathrm{~mW})$ instrumented using inertial sensors. Tinetti Gait, Tinetti Balance, Gait Status Scale, and Grading Scale were fulfilled before and $72 \mathrm{~h}$ after the CSF-TT. Stride length, cadence and total time were selected as the outcome measures. Statistical models with mixed effects were implemented to determine the relevant contribution to response variables of each quantitative gait parameter and clinical scales.
\end{abstract}

Results and conclusion: From baseline to $72 \mathrm{~h}$ post CSF-TT patients improved significantly by increasing cadence in 18 $\mathrm{mW}$ and TUG (on average of 1.7 and 2.4 strides/min respectively) and stride length in $18 \mathrm{~mW}$ (on average of $3.1 \mathrm{~cm}$ ). A significant reduction of gait apraxia was reflected by modifications in double support duration and in coordination index. Tinetti Gait, Tinetti Balance and Gait Status Scale were able to explain part of the variability of response variables not covered by instrumental data, especially in TUG. Grading Scale revealed the highest affinity with TUG total time and cadence when considering clinical scales alone.

Patients with iNPH and an associated vascular encephalopathy showed worst performances compared to pure iNPH but without statistical significance. Gait improvement following CSF-TT was comparable in the two groups. Overall these results suggest that, in order to augment CSF-TT accuracy, is key to assess the gait pattern by analyzing the main spatiotemporal parameters and set post evaluation at $72 \mathrm{~h}$.

Trial registration: Approved by ethics committee: CE 14131 23/02/2015.

Keywords: Idiopathic normal pressure hydrocephalus, Inertial measurement units, Gait analysis, TUG test, CSF tap test

\footnotetext{
* Correspondence: alberto.ferrari@unibo.it

${ }^{1}$ Health Sciences and Technologies - Interdepartmental Center for Industrial Research (CIRI-SDV), Alma Mater Studiorum - University of Bologna, Bologna, Italy

Full list of author information is available at the end of the article
}

(c) The Author(s). 2020 Open Access This article is distributed under the terms of the Creative Commons Attribution 4.0 International License (http://creativecommons.org/licenses/by/4.0/), which permits unrestricted use, distribution, and reproduction in any medium, provided you give appropriate credit to the original author(s) and the source, provide a link to the Creative Commons license, and indicate if changes were made. The Creative Commons Public Domain Dedication waiver (http://creativecommons.org/publicdomain/zero/1.0/) applies to the data made available in this article, unless otherwise stated. 


\section{Background}

Idiopathic normal pressure hydrocephalus (iNPH) is a syndrome characterized by chronic ventricular dilation, normal cerebrospinal fluid (CSF) pressure and the triad of symptoms: gait apraxia, urinary incontinence, and cognitive deficits [1]. Treating iNPH with the insertion of a ventricular peritoneal shunt allows draining excessive cerebrospinal fluid, [2] which in turn can lead up to a complete recovery $[2,3]$. A recent systematic review reported symptoms improvement following shunt insertion in $71 \%$ of the three thousand patients analyzed in 64 published studies [3].

Still, the diagnosis of iNPH is complicated due to the considerable variability in its clinical presentation and course. Following current consensus guidelines, iNPH should be diagnosed from clinical history, physical examination, and brain imaging $[2,4,5]$. Practically, it is usually identified by the exclusion of other conditions once specific treatments for Parkinsonism or musculoskeletal diseases are ineffective. Nonetheless, a delayed diagnosis causes a disease progression to a point where treatment may be no longer effective [6].

The gait of iNPH patients is usually described as bradykinetic, shuffling, unstable on turning and with reduced walking speed [4]. Besides, it is typically magnetic, with an increased double support duration witnessing a difficulty in limb rising and step initiation [7]. Overall gait is apraxic, and this is usually the most disabling symptom and first sign onset, whereas cognitive impairment and urinary incontinence might appear in a later stage [4]. Gait apraxia is a common symptom also in patients affected by vascular encephalopathy [8]. Thus, iNPH and vascular encephalopathy conditions are often confused with each other. Moreover, vascular encephalopathy might result as a comorbidity of iNPH, potentially limiting the effectiveness of surgical treatment.

Supplementary prognostic tests, e.g., CSF tap-test (CSF-TT), have been used to attain a higher specificity and sensitivity for diagnosing iNPH and for predicting shunt response [2, 9]. The rationale is that temporary symptoms improvement from CSF drainage is prognostic for following shunt insertion. In a recent review study from Mihalj et al., the accuracy of CSF-TT in screening patients for shunting is $62 \%$, but its negative predictive value is merely $37 \%$ [10]. This latter unsatisfactory result can be potentially ascribed to the use of ineffective tools in the analysis of post-CSF-TT improvements. In fact, the measure of gait changes is frequently based on qualitative, examiner-based evaluations rather than quantitative analyses, possibly leading to a misinterpretation of the findings [11]. Gait is commonly evaluated with the $10-\mathrm{m}$ walking test $(10 \mathrm{~mW})$ having the test duration as a single outcome, or by clinical scales such as the iNPH
Grading Scale [12]. This latter, in particular, is a clinicianrated scale aimed at separately assessing the severity of each of the three main symptoms [13]. As well, the Gait Status Scale was explicitly designed for analyzing gait disturbances of iNPH patients on the base of simple clinical observations [13].

Instrumented gait analysis may conversely be a crucial tool to augment CSF-TT accuracy allowing to objectively assess the improvements through a precise measure of the gait pattern [7]. Among different systems available for gait analysis, inertial measurement units (IMUs) are nowadays opening new perspectives in instrumenting motor tests [14]. The latest generation of IMUs are indeed wireless, small, lightweight, cost-effective and operating in real-time, therefore allowing the plugand-play execution of gait analysis tests in the times of clinical routine [15]. Besides, the use of apps for mobile devices allows us to run the tests in any environment and to have detailed reports right after their executions $[15,16]$.

Just a few studies investigated the effects of CSF-TT through an instrumented gait analysis. Among these, Stolze et al. in a study involving 10 iNPH patients, reported gait speed and stride length as the most responsive parameters in a pre- vs. $24 \mathrm{~h}$ post-CSF-TT comparison, whereas cadence and balance remained unaffected [17]. More recently, Panciani et al. compared gait performances on 52 iNPH patients pre vs. few hours post-CSF-TT finding improvements in gait speed, stride length and double support duration [18]. Another study compared performances on a timed-up and go test (TUG) pre vs. $24 \mathrm{~h}$ post-CSF-TT revealing significant improvements in the sit-to-stand transition, walking time, and the number of steps employed to turn [19]. Allali et al. found a significant improvement of gait speed in single and dual tasking of $10 \mathrm{~mW}$ in a pre vs. $24 \mathrm{~h}$ post-CSF-TT [20]. In a study involving 74 patients, significant differences pre and $2-4 \mathrm{~h}$ post-CSF-TT were revealed for the Performance Oriented Mobility Assessment (Tinetti, [21]) and the Berg Balance Scale. Partially in contrast with these findings, TUG and $10 \mathrm{~mW}$ revealed improvements just in those patients assessed as eligible for shunt neurosurgery [22].

Gait changes after CSF-TT is a transient phenomenon, but literature does not offer an agreement about when it is the time point where the maximal modification can be expected [10]. Several studies analyzed the motor performances of patients not after a predefined amount of time, but on different days [23]. Other studies provided evidence of improvement within the first $24 \mathrm{~h}$ [7, 11, 18, 22]. In particular, Virhammar et al. reported improvements in gait speed of $10 \mathrm{~mW}$ since $1 \mathrm{~h}$ to $24 \mathrm{~h}$ post-CSF-TT [12]. On the contrary, many other studies recommend examining patients performances since the second day after the CSF- 
TT [17, 19, 20, 24]. Recently, Schniepp et al. examined 24 iNPH patients employing sequential recordings of gait velocity from $1 \mathrm{~h}$ to $72 \mathrm{~h}$ [25]. The maximal increase was observed in single-tasking after $24 \mathrm{~h}$ to $48 \mathrm{~h}$, whereas in dual-tasking after $48 \mathrm{~h}$ to $72 \mathrm{~h}$. The low negative predictive value in screening patients for shunting of CSF-TT (37\%) might also depend on post evaluations not acquired on the appropriate time point [25].

The aim of this paper was threefold: i) to determine the contribution of gait analysis data obtained using IMUs and clinical scales on assessing pre vs. post-CSFTT modifications in motor performance, ii) to determine the influence of the association between iNPH and vascular encephalopathy on CSF-TT outcomes, and iii) to evaluate whether CSF-TT effect on gait performance is more relevant after 24 or $72 \mathrm{~h}$.

\section{Methods \\ Participants}

This observational prospective study was conducted between May 2015 to May 2018 in the Institute of Neurological Sciences (IRCCS) of Bologna, a national referral neurological and neurosurgical inpatient facility. Population eligible for inclusion in the study consisted of subjects: i) aged over 50 years old, ii) presenting at least one of the symptoms of the iNPH clinical triad [4], and iii) able to give verbal and written informed consent. Exclusion criteria were: i) the presence of severe psychiatric disease or physical illness, and ii) addiction to drugs. Patients eligible were admitted for investigation of iNPH by referral from neurologists, geriatricians, neurosurgeons and general practitioners and scheduled for a 3-Tesla-MRI brain scan. Patients with a clinical history possibly causing ventricular dilation, such as subarachnoid hemorrhage, meningitis, head injury, congenital hydrocephalus or aqueductal stenosis, were excluded. The diagnosis was assigned after reviewing: i) clinical data, ii) neuroimages, iii) neuropsychological information, and iv) blood and CSF composition tests during a consensus case conference comprising neurologists, neurosurgeons, neuropsychologists, neuroradiologists, physiatrists and nurses of the Institute of Neurological Sciences (IRCCS) of Bologna [26].

White matter changes were quantified on neuroimages with the Age-Related White Matters Changes (ARWMC) scale [27]. In this scale, the frontal, the parieto-occipital, the temporal, the infratentorial and the basal ganglia areas of right and left hemisphere are individually rated with a score ranging from 0 to 3 according to the number and degree of confluence of lesions. iNPH patients were classified in pure hydrocephalus (p-iNPH) or hydrocephalus with important vascular encephalopathy $(\mathrm{v}-\mathrm{iNPH})$ in case the overall score of ARWMC was respectively below or above 10. Considering the absence in the literature of a validated cut-off value, the one here proposed was established based on the expert opinion of the neuroradiologist.

This study was approved by the local ethics committee of the health service of Bologna, reference CE 14131 23/ $02 / 2015$, and was conducted in agreement with principles of good clinical practice. All participants gave their written consent to participation according to the declaration of Helsinki.

\section{Protocol}

The CSF-TT consisted in the removal of $30-40 \mathrm{ml}$ of CSF using a 20-gauge spinal needle in lateral supine position.

Gait was assessed by TUG being the standard motor test in studies involving iNPH patients to assess balance and mobility [28], and by $10 \mathrm{~mW}$ extended to the distance of $18 \mathrm{~m}(18 \mathrm{~mW})$, as proposed by Kahlon et al. [29]. During TUG patients raised from a chair with armrests, walked $3 \mathrm{~m}$ forward, turned $180^{\circ}$ around a traffic cone, walked $3 \mathrm{~m}$ backward and sat back on the same chair. During $18 \mathrm{~mW}$ patients were instructed to walk on a straight line at a self-selected pace along a large and empty corridor $30 \mathrm{~m}$ long. Both tests were repeated three times in order to filter out the effect due to habituation or lack of attention. Gait was quantitatively assessed by TUG pre- (baseline), $24 \mathrm{~h}$ - (T24 h) and $72 \mathrm{~h}$ (T72 $\mathrm{h}$ ) post-CSF-TT and by $18 \mathrm{~mW}$ at baseline and $\mathrm{T} 24 \mathrm{~h}$. In order to better infer the performance modification along the three time points, on the firsts 15 patients $(10 \mathrm{p}$-iNPH and $5 \mathrm{v}$-iNPH $)$ the $18 \mathrm{~mW}$ was also acquired at $\mathrm{T} 72 \mathrm{~h}$.

The TUG and $18 \mathrm{~mW}$ were instrumented using mGAIT (mHealth Technologies, Italy). In particular, three inertial sensors equipped with a triaxial accelerometer (full scale set at $\pm 8 \mathrm{~g}$ ) and a triaxial gyroscope (full scale set at $\pm 1000^{\circ} / \mathrm{s}$ ) and with a sampling rate of $100 \mathrm{~Hz}$ were wore two on the shoes and one on the lower trunk [30]. The sensors connected via Bluetooth to an Android smartphone using an app which functioned as a portable processing platform. The app implemented ad-hoc algorithms to detect the gait cycle events and an extended Kalman filter with zero velocity updates to determine the spatial gait parameters using the same framework reported in Ferrari et al. [15]. Threshold values and conditional expressions of the algorithms were tuned based on data coming from pathological gait patterns of patients with major neurological conditions.

Gait data were processed in real-time. At the end of tests the app provided the following parameters for analysis: i) test total time, ii) gait speed, iii) stride length, iv) cadence, v) phases of the gait cycle (duration of single and double support expressed as percentage of gait cycle, stance and swing), vi) phase coordination index 
(PCI) as a measure of gait coordination [31]. The trunk acceleration signals recorded during the TUG were processed, using Matlab 2017b (Mathworks Inc., USA), similarly to Palmerini et al. [32]. In particular, the trunk inclination was obtained through an inverse pendulum model as the arcsin of the vertical component of the acceleration normalized to gravity and zeroed to the initial sitting position. The following parameters were determined: vii) sit-to-stand duration, viii) number of steps to turn, ix) stand-to-sit duration, and $\mathrm{x}$ ) time taken to walk.

At baseline and $\mathrm{T} 72 \mathrm{~h}$ the following clinical scales were fulfilled: 1) Grading Scale, 2) Tinetti, 3) Gait Status Scale. For Grading Scale and Gait Status Scale, higher scores indicate more impaired motor abilities. Tinetti consists of: i) a balance section (Tinetti Balance), assessing 9 items scored out of 16 points, ii) a gait section (Tinetti Gait), assessing 8 items scored out of 12 points, and iii) a combined score (Tinetti) of 28 points as a result of the sum of the previous two. Higher scores mean less impaired motor abilities.

\section{Statistical analysis}

Following what observed by Hollman et al. [33], in order to carefully evaluate all the complimentary aspects of gait that contribute to a modification in motor performance as a result of the CSF-TT, three parameters were selected as main responsive variables: i) cadence, ii) stride length, and iii) test total time.

With the goal of reducing measurement error, averaging of repeated measurements is common practice when analyzing outcomes in clinical research. However this procedure also removes useful information [34]. Furthermore, without properly considering test repetitions at the same time point as repeated within-subject measurements, efficiency and statistical power worsen. As also recently recommended by an editorial of Gait and Posture by Prescott RJ [35], the use of a linear model with mixed effects on non-averaged data can conversely properly account for correlation between repeated measurements, keep the narrowest confidence intervals for clinical parameters, hold the greatest statistical efficiency [36], and flexibly model time effects [37].

In this study, linear models with mixed effects were implemented using backward elimination for each of the three main responsive variables using $R$ (https://www.rproject.org/). Backward elimination is a stepwise procedure that consists in including all the candidate variables to fit the statistical model and that, at each step, deletes the regressor (if any) whose loss gives most statistically insignificant deterioration to the fit of the reduced model, until no further variables can be deleted without a statistically significant loss of fit. Eq. 1 reports the complete model from which started the analysis of spatio-temporal gait parameters as regressors to the three response variables:

Equation 1: Complete linear model with mixed effects used to determine effect of CSF-TT on modification of motor performance during instrumented TUG and 18 $m W$

$$
\begin{aligned}
\text { PerformanceMeasure }_{\text {irt }}= & \beta_{0}+\beta_{1} T_{i}+\text { age }_{i}+\text { BMI }_{i} \\
& + \text { diagnosis }_{i} \\
& + \text { doubleSupportDuration }_{\text {irt }} \\
& + \text { PCI }_{\text {irt }}+\text { turningSteps }_{\text {irt }} \\
& + \text { sitToStand }_{\text {irt }} \\
& + \text { standToSit }_{\text {irt }} \\
& + \text { walkTime }_{i r t}+b_{0 i t} \\
& +\varepsilon_{\text {irt }} \equiv \mu_{i t}+b_{0 i t}+\varepsilon_{i r t}
\end{aligned}
$$

where PerformanceMeasure irt $_{\text {is }}$ is the value of cadence, stride length or total time for the $r$-th measurement made at time $t(t=$ baseline, T24 h, T72 h) on the $i$-th subject; $\beta_{0}$ is the constant term, $\beta_{1} T_{i}$ is the term that models the trend of PerformanceMeasure along the three time points $t$. This model also includes an occasionalspecific random intercept for each subject $b_{0 i t}$, that takes into account possible correlations among the three test repetitions on same $t$.

In order to evaluate the contribution of clinical scales in addition to gait analysis parameters, to the three models reported in Eq. 1, the scores of Gait Status Scale, Tinetti Balance, Tinetti Gait, Tinetti, and Grading Scale were added, and the ones relative to $\mathrm{T} 24 \mathrm{~h}$ were removed (Eq. 2). Proceeding likewise for Eq. 1, final fitting of the regression models was carried with backward elimination.

Equation 2: Complete linear model with mixed effects used to determine effect of CSF during instrumented TUG and $18 \mathrm{~mW}$ using spatio-temporal gait parameters and clinical scales scores as regressors

$$
\begin{aligned}
\text { PerformanceMeasure }_{i r t}= & \beta_{0}+\beta_{1} T_{i}+\text { age }_{i}+\text { BMI }_{i} \\
& + \text { diagnosis }_{i} \\
& + \text { doubleSupportDuration }_{\text {irt }} \\
& + \text { PCI }_{\text {irt }}+\text { turningSteps }_{\text {irt }} \\
& + \text { sitoStand }_{\text {irt }} \\
& + \text { standToSit }_{i r t} \\
& + \text { walkTime }_{\text {irt }} \\
& + \text { Gait Status Scale }_{i t} \\
& + \text { Tinetti Balance }_{i t} \\
& + \text { Tinetti Gait }_{i t}+\text { Tinetti }_{i t} \\
& + \text { Grading Scale }_{i t}+b_{0 i t} \\
& +\varepsilon_{\text {irt }} \equiv \mu_{i t}+b_{0 i t}+\varepsilon_{i r t}
\end{aligned}
$$

Subscripts apply as in Eq. 1.

Finally, with the aim of analyzing the behavior of clinical rating scales alone with respect to responsive variables, a 
linear mixed model was realized using scores of clinical scales as the only predictors (Eq. 3).

Equation 3: Complete linear model with mixed effects used to determine effect of CSF-TT using clinical scales scores as regressors

$$
\begin{aligned}
\text { PerformanceMeasure }_{i r t}= & \beta_{0}+\beta_{1} T_{i}+\text { age }_{i}+\text { BMI }_{i} \\
& + \text { diagnosis }_{i} \\
& + \text { Gait Status Scale }_{i t} \\
& + \text { Tinetti Balance }_{i t} \\
& + \text { Tinetti Gait }_{i t}+\text { Tinetti }_{i t} \\
& + \text { Grading Scale }_{i t} \\
& +\varepsilon_{\text {irt }} \equiv \mu_{i t}+\varepsilon_{\text {irt }}
\end{aligned}
$$

Subscripts apply as in Eq. 1.

The contribution of each term on the right side of the three former equations, in the attempt to explain the variance of the three responsive variables on the left side, has been processed by the linear mixed models and eliminated just in case the deterioration to the fit of the reduced model was statistically insignificant.

\section{Results \\ Participant flow}

Among the 151 persons with suspicion of iNPH referred at IRCCS Institute, 76 patients received a diagnosis of iNPH. Fifty-six were p-iNPH forms whereas 20 were viNPH. Table 1 reports demographical, clinical and neurological characteristics of the iNPH sample and the number of motor test acquisitions.

Patients unable to walk at baseline were excluded from the following analyses. Final dataset consisted of 45 p-iNPH (mean age (standard deviation): 73.9 (5.0)

\begin{tabular}{|c|c|c|c|}
\hline & Total & $\mathrm{p}$-iNPH & $\mathrm{v}$-iNPH \\
\hline \multicolumn{4}{|l|}{ Demographic } \\
\hline Subjects & 76 & 56 & 20 \\
\hline Males (\%) & $43(57)$ & $31(55)$ & $12(60)$ \\
\hline Mean age at disease onset (st. Dev) & $72(5.7)$ & $71(6.2)$ & $73(3.3)$ \\
\hline Mean age at evaluation (st. Dev) & $75(4.7)$ & $74(5.1)$ & $77(3.0)$ \\
\hline Disease duration $<12$ months & 21 & 18 & 3 \\
\hline Disease duration $>12$ months & 55 & 38 & 17 \\
\hline BMI, [kg/m²] (st. Dev) & $27(4.1)$ & $28(3.9)$ & $25(4.1)$ \\
\hline \multicolumn{4}{|l|}{ Clinical profile } \\
\hline \multicolumn{4}{|l|}{ Symptoms at first evaluation } \\
\hline 1, subjects (\%) & $6(8)$ & $6(11)$ & 0 \\
\hline 2 , subjects (\%) & $18(24)$ & $13(23)$ & $5(25)$ \\
\hline 3, subjects (\%) & $52(68)$ & $37(66)$ & $15(75)$ \\
\hline gait disorders, subjects (\%) & $76(100)$ & $56(100)$ & $20(100)$ \\
\hline urinary dysfunctions, subjects (\%) & $63(83)$ & $47(84)$ & $16(80)$ \\
\hline cognitive impairments, subjects (\%) & $58(76)$ & $39(70)$ & $19(95)$ \\
\hline \multicolumn{4}{|l|}{ Number of falls in the last 6 months } \\
\hline $0,(\%)$ & $17(22)$ & $12(21)$ & $5(25)$ \\
\hline 1, (\%) & $15(20)$ & $12(21)$ & $3(15)$ \\
\hline$\geq 2,(\%)$ & $44(58)$ & $32(57)$ & $12(60)$ \\
\hline Mean ARWMC (st. Dev) & $7.2(4.6)$ & $5.0(2.7)$ & $13.7(2.3)$ \\
\hline \multicolumn{4}{|l|}{ Motor tests } \\
\hline TUG total trials acquired & 585 & 405 & 180 \\
\hline TUG discarded (incomplete acquisitions) & $31(5 \%)$ & $22(5 \%)$ & $9(5 \%)$ \\
\hline $18 \mathrm{~mW}$ total trials acquired & 405 & 300 & 135 \\
\hline $18 \mathrm{~mW}$ discarded (incomplete acquisitions) & $32(8 \%)$ & $21(7 \%)$ & $11(8 \%)$ \\
\hline
\end{tabular}
years; BMI: $28.1(3.8) \mathrm{kg} / \mathrm{m}^{2}$ ) and $20 \mathrm{v}$-iNPH (mean age (standard deviation): 76.7 (3.1) years; BMI: 25.1 (4.0) $\mathrm{kg} / \mathrm{m}^{2}$ ). These groups differed significantly in terms of mean age (t-test, $p<0.01)$ and mean BMI (t-test, $p<$ $0.01)$; age and BMI were therefore included in the

Table 1 Baseline demographic, clinical and neurological characteristics of subjects and number of motor test acquisitions

BMI Body mass index; ARWMC Age-Related White Matters Changes 
regression model to study their possible differential effect on performance (Eq. 1).

\section{Instrumental gait analysis of TUG and $18 \mathrm{~mW}$}

A total of 585 trials were acquired using mGAIT. Few of these trials were not completed either because patients lost focus on the task to accomplish or because they were too demanding from the physical point of view and were excluded from following analysis (Table 1). Three hundred eighty-three TUG and $27918 \mathrm{~mW}$ trials for piNPH patients plus 171 TUG and 124 $18 \mathrm{~mW}$ trials for $\mathrm{v}$-iNPH patients were finally considered for the statistical analysis. Figure 1 shows a typical IMUs recording for TUG and $18 \mathrm{~mW}$ relative to a p-iNPH subject acquired at T24 h. In particular, heel strikes and foot offs are superimposed on top of shoes medio-lateral angular velocities; as well starts and ends of sit-to-stand and stand-to-sit phases on top of trunk antero-posterior acceleration. Figure 2 shows in a radar chart the progression, for the two groups and the two motor tests, of the median cadence, stride length, total time, total steps, double support, and gait speed along the three time points (baseline, T24 h and T72 h) using normative data as reference. Figure 3 shows more in detail via box plots all values obtained for gait speed across the two groups, the three time points, and the two motor tests.

Table 2 reports the final statistical model, after regressor selection via backward elimination. Comparing results at baseline vs. T24 h and T72 h, the TUG disclosed a statistically significant improvement for cadence both at T24h $(p<0.01)$ and T72 h $(p<0.001)$, for total time just at T72 h $(p<0.05)$, whereas stride length modifications were statistically not relevant. The $18 \mathrm{~mW}$ revealed both for stride length and cadence an improvement at $\mathrm{T} 24 \mathrm{~h}(p<0.05$ and $p<0.001$, respectively) and at $\mathrm{T} 72 \mathrm{~h}$ ( $p<0.05$ in both cases), however total time never showed the time effect as significant. Belonging to $p$ iNPH or v-iNPH did not provide a relevant contribution to explain any of the outcome measures. However, values obtained disclosed on average a decreased performance of $\mathrm{v}$-iNPH subjects compared to $\mathrm{p}$-iNPH subjects, with a trend towards significance in $18 \mathrm{~mW}$ where $\mathrm{v}$-iNPH showed on average an increase of $2 \mathrm{~s}$ on test total time.

The change in stride length, cadence and total time measured with TUG, other than pre vs. post comparison, was mostly predicted by the reduction of the duration of double support, the number of turning steps, and the value of PCI. In particular, double support duration showed a high statistical significance $(p<0.001)$ across the two motor tests, where to its unitary increment corresponded an average decrease of stride length (of $1.6 \mathrm{~cm}$ in TUG and $1.9 \mathrm{~cm}$ in $18 \mathrm{~mW}$ ), and cadence (of 0.3 in TUG and 0.4 strides/min in $18 \mathrm{~mW}$ ) and, on average, an increase of total time (of $0.6 \mathrm{~s}$ in TUG and $1.2 \mathrm{~s}$ in $18 \mathrm{~mW}$ ). The time to complete TUG was also explained by duration of sit-to-stand and stand-to-sit phases. As well, the $18 \mathrm{~mW}$ was predicted both by the duration of double support and PCI.

In order to verify the homoscedasticity of random effects, the Levene test was performed on model residuals and reported in Table 3. In particular, the variability among subjects excluding the time effect, the variability among time points including all subjects' trials, and the intersection between these latter two were considered.

The homoscedasticity of random effects is never present $(p<0.003)$ when the inter-subject variability alone is considered (Table 3 ), showing how patients performances differ considerably among themselves and along time points. On the contrary, during TUG along time homoscedasticity is always present $(p>0.3)$ showing how overall variability at baseline, T24 h and T72 h did not differ. Also on $18 \mathrm{~mW}$ homoscedasticity is present along time for cadence but not for stride length and total time, testifying how from baseline to $\mathrm{T} 72 \mathrm{~h}$ the variability changed. Finally, considering the time-subject interaction the homoscedasticity is always present both for TUG and $18 \mathrm{~mW}$ except for the outcome total time in TUG $(p<0.05)$.

\section{Clinical scales}

The clinical scales were fulfilled on 56 p-INPH and 20 $\mathrm{v}$-iNPH patients. However, in few cases patients were not able to perform clinical test tasks; Table 4 reports mean, standard deviation and number of patients able to execute the tests. At baseline, v-iNPH patients presented on average higher mean values for Gait Status Scale when compared to p-iNPH, 6.4 vs. 5.5 respectively, but without reaching statistical significance. Tinetti Balance, Tinetti gait, Tinetti, and Grading Scale also did not show relevant differences between groups (Table 4).

Table 5 reports final fitting of the regression models of the contribution of clinical scales in addition to gait analysis parameters as specified in Eq. 2.

Considering the results of TUG, reported in Table 5, compared to the ones relative to the model of Eq. 1, PCI remained significant just in the prediction of total time. Both Tinetti Gait and Gait Status Scale were not eliminated from the model fitting of stride length and in correspondence to their unitary increment, stride length increased respectively of $1.2 \mathrm{~cm}$ and decreased of $1 \mathrm{~cm}$, on average. Grading Scale, as well, was considered as an explanatory variable in prediction of cadence with an average increase of 0.6 strides/min per its unitary increment. Finally, Tinetti Balance was the only clinical scale remaining in the prediction of total time, providing a contribution more relevant with respect to sit-to-stand 
A

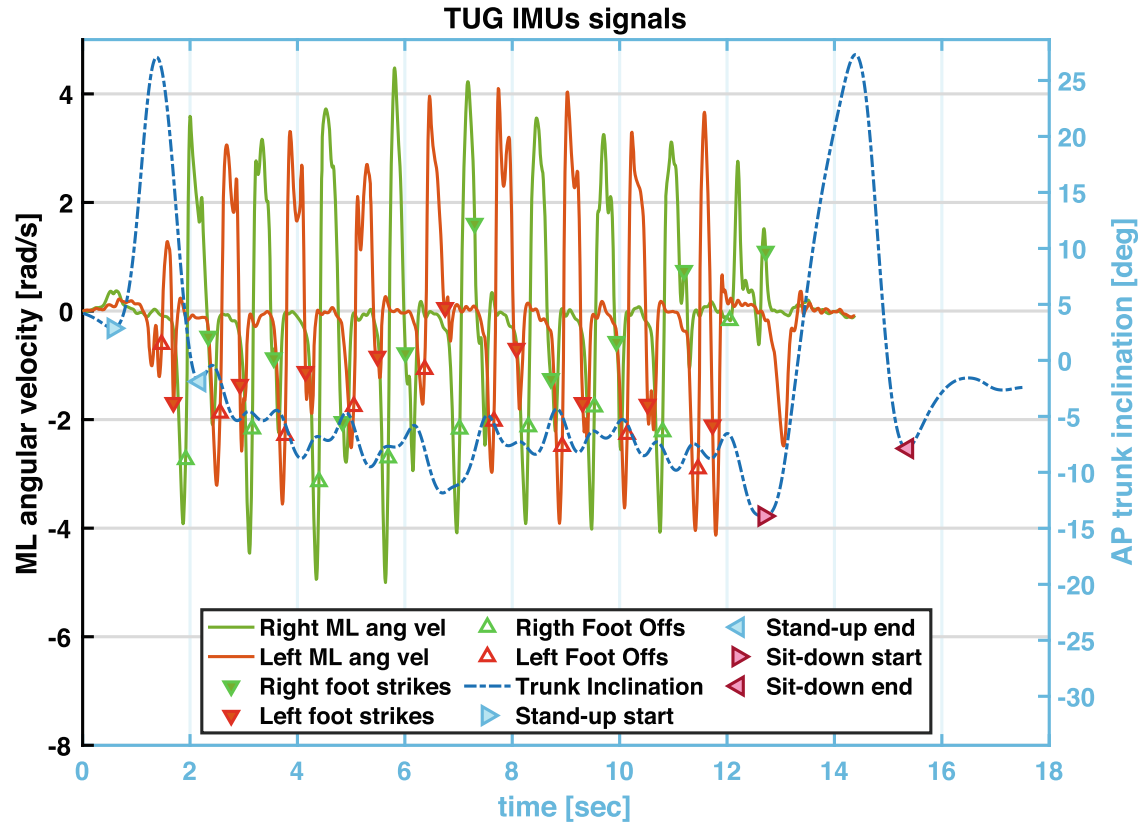

B

$18 \mathrm{~mW}$ IMUs signals

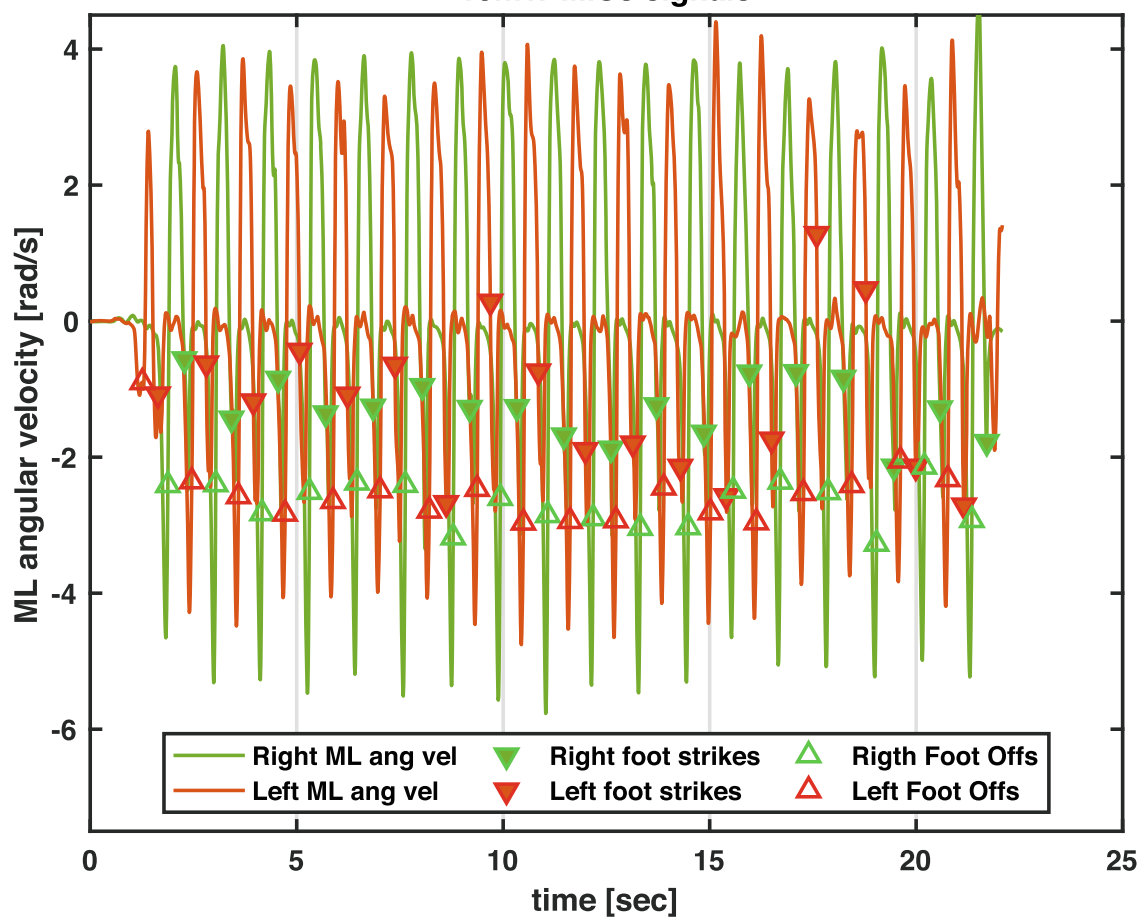

Fig. 1 Typical IMUs recording for a) TUG and b) $18 \mathrm{~mW}$ of a p-iNPH subject acquired at T24 h. Heel strikes (downward triangles) and foot offs (upward triangles) are superimposed on top of shoes medio-lateral angular velocities (right in green and left in red); as well, starts (rightward triangles) and ends (leftward triangles) of sit-to-stand and stand-to-sit phases are shown (when present) on the antero-posterior inclination (in blue) recorded from the sensor placed on lower back 


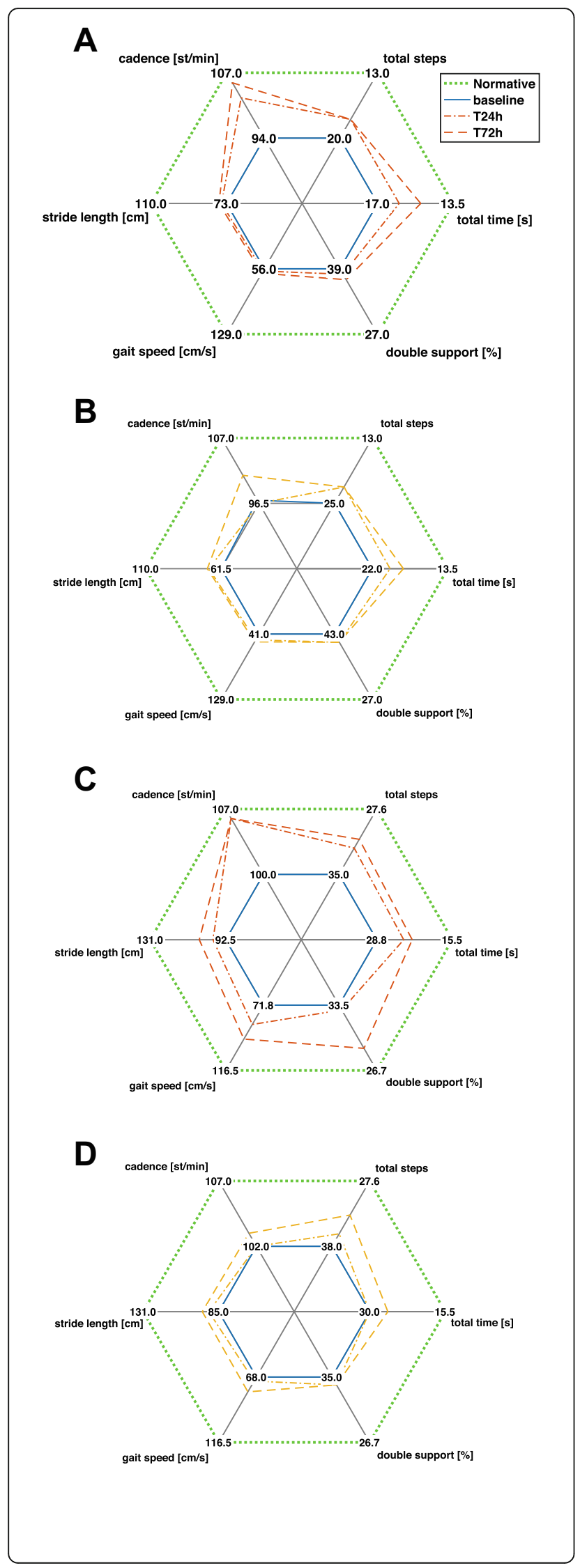

Fig. 2 Radar plots of the progression of median values of cadence, stride length, total time, total steps, double support, and gait speed for a p-iNPH on TUG, b v-iNPH on TUG, c p-iNPH on $18 \mathrm{~mW}$ and $\mathbf{d}$ $\mathrm{v}$-iNPH on $18 \mathrm{~mW}$ from baseline to $\mathrm{T72} \mathrm{h}$. Distances are normalized with respect to baseline (blue lines) and normative values (green dot lines) derived for TUG from [18, 38]; for $18 \mathrm{~mW}$ from [33]. Red plots refer to the p-iNPH group, yellow plots to the $\mathrm{v}$-iNPH group. Cadence is expressed in steps per minute

time and turning steps. TUG total time decreased on average of $0.9 \mathrm{~s}$ per single increment of Tinetti Balance.

When considering cadence in $18 \mathrm{~mW}$ results (Table 5), all scales gave statistically insignificant deterioration to the fit of the reduced model and were therefore eliminated. Tinetti gait was the only scale not eliminated for total time, which was reduced of $1.4 \mathrm{~s}$, on average, per its unitary increment. Tinetti Gait, Grading Scale and Tinetti Balance gave their relevant contribution to explain stride length variability. In correspondence of a unitary increment of Tinetti Gait, Grading Scale and Tinetti Balance, stride length respectively increased of $2.8 \mathrm{~cm}$ and decreased of $1.6 \mathrm{~cm}$ and $2 \mathrm{~cm}$, on average. As in previous model, the homoscedasticity of random effects was verified by means of the Levene test on model residuals (Table 6).

Same considerations as for the model described by Eq. 1 can be applied here. In the interaction timesubject the homoscedasticity is always present both for TUG and $18 \mathrm{~mW}$ except for the outcome total time in TUG $(p<0.001)$.

The contribution of clinical rating scales alone to explain responsive variables, as detailed in Eq. 3, is reported in Table 7 During TUG stride length was predicted with statistical significance by Gait Status Scale, with a unitary increase of this scale producing a stride $1.7 \mathrm{~cm}$ shorter, on average. For $18 \mathrm{~mW}$, other than Gait Status Scale shortening on average the stride of $2.3 \mathrm{~cm}$ per unitary increment, Tinetti Gait was also not eliminated producing a stride $5.9 \mathrm{~cm}$ longer per unitary increment, on average. Grading scale significantly contributed to explain total time and cadence variability during TUG, with its unitary increment determining respectively an increase of $1.8 \mathrm{~s}$ and a decrease of 0.9 strides/ min, on average. Time effect resulted also statistically relevant for cadence both during TUG and $18 \mathrm{~mW}$ (Table 7).

\section{Discussion}

This observational cohort study is one of the largest monocentric studies carried out so far on idiopathic normal pressure hydrocephalus, a complex and often misdiagnosed syndrome. In this study, out of 151 patients with suspected hydrocephalus from brain imaging and at least one symptom of the classical triad, 76 were 
A
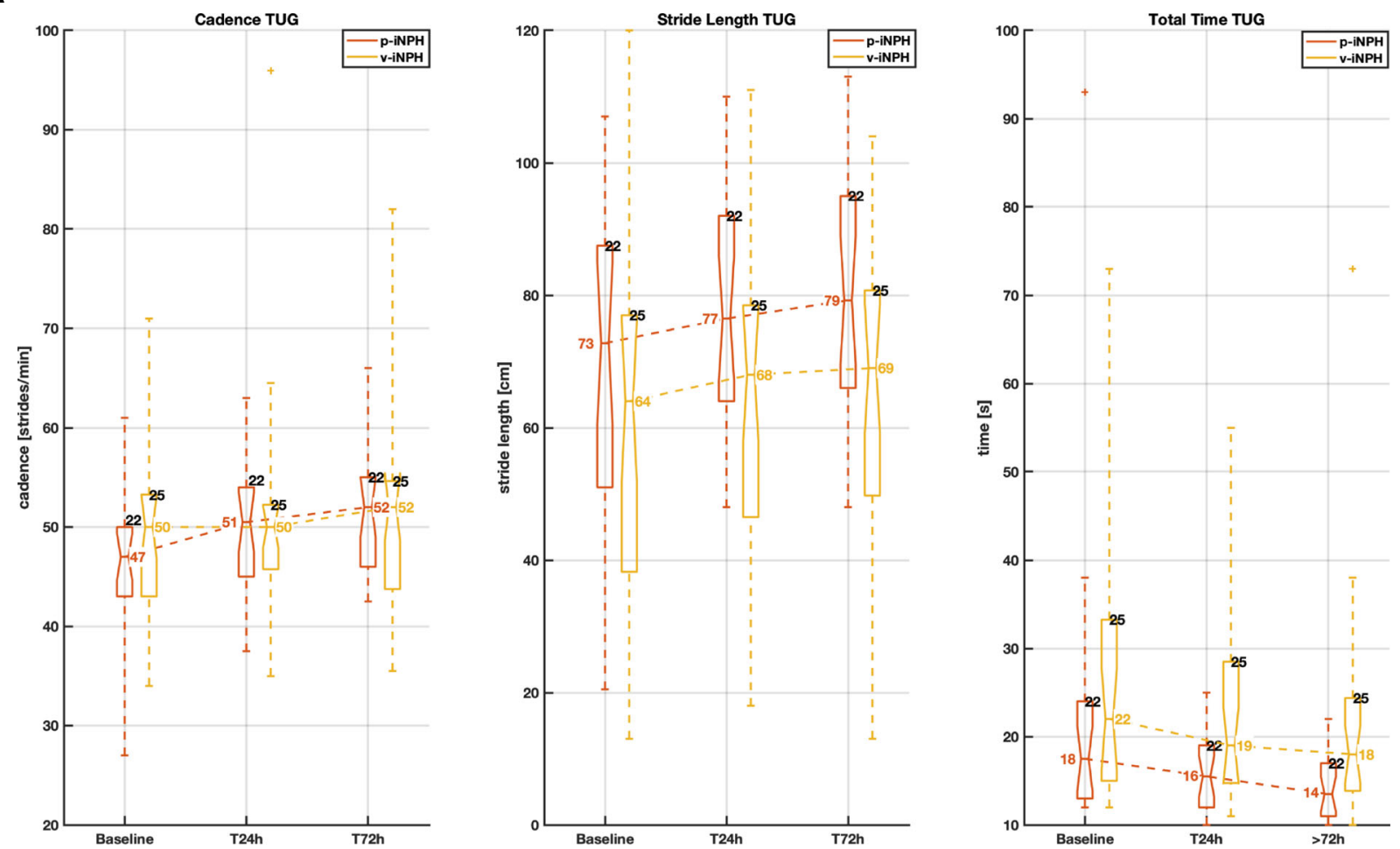

B
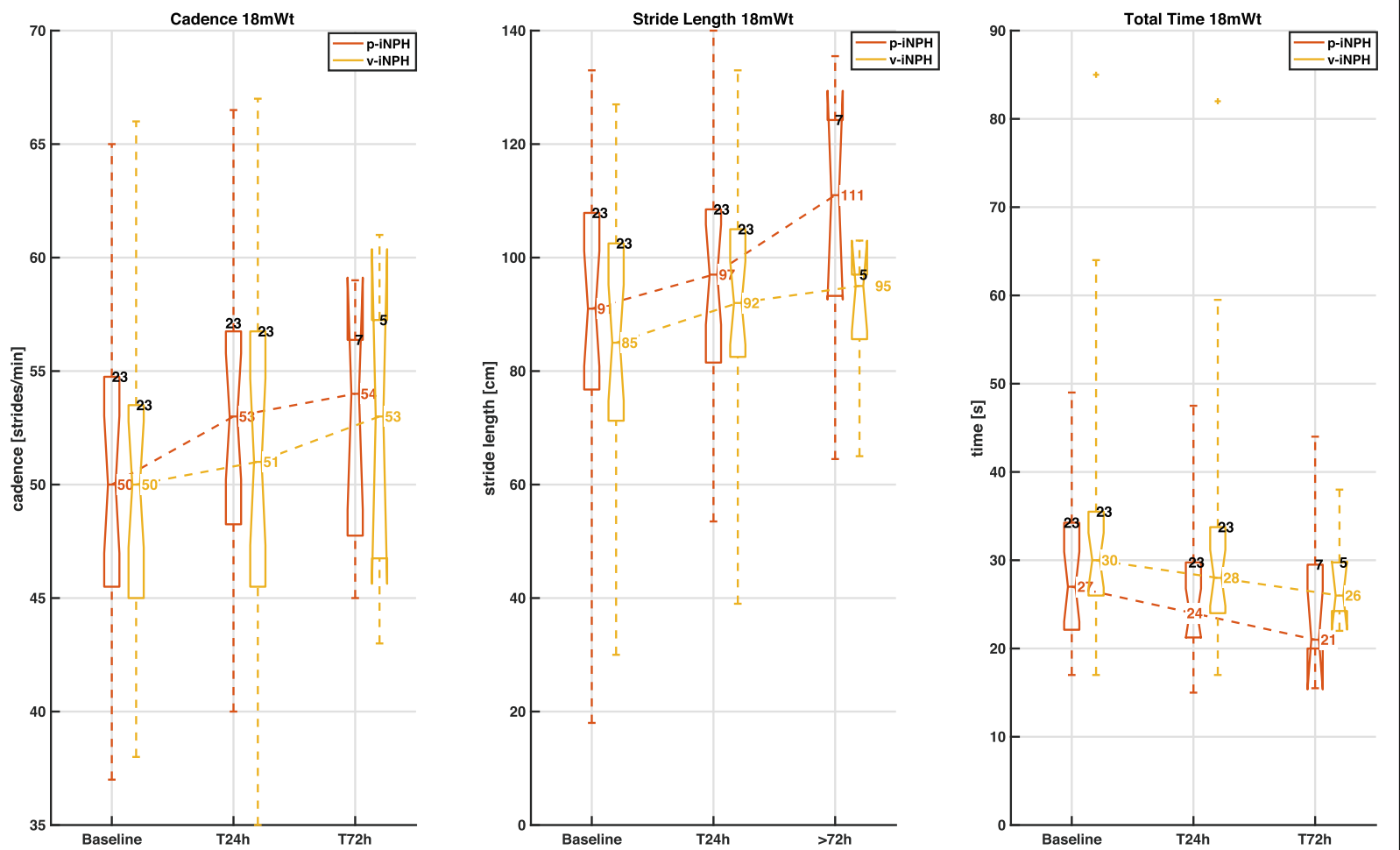

Fig. 3 Box plot of all values obtained for responsive variables cadence, stride length and total time along the three time points baseline, T24 $\mathrm{h}$ and $\mathrm{T} 72 \mathrm{~h}$, and the two motor tests a TUG, and b $18 \mathrm{~mW}$. Red boxes refer to the p-iNPH group (numbers in red report the median value), yellow boxes to the v-iNPH group (numbers in yellow report the median value). A single median value for the three repetitions was considered. Numbers in black represent the number of patients who successfully completed the tests 
Table 2 Results of the three linear models with mixed effects built on the responsive variables stride length, cadence and total time (Eq. 1) from gait analysis data of TUG and $18 \mathrm{~mW}$ at baseline, $T 24 \mathrm{~h}$ and $\mathrm{T} 72 \mathrm{~h}$

\begin{tabular}{|c|c|c|c|c|c|c|}
\hline & \multicolumn{3}{|l|}{ TUG } & \multicolumn{3}{|l|}{$18 \mathrm{~mW}$} \\
\hline & & Value & $p$-value & & Value & $\overline{p \text {-value }}$ \\
\hline \multirow[t]{7}{*}{ Stride length $[\mathrm{cm}]$} & (Intercept) & 140.3 & 0.000 & (Intercept) & 157.2 & 0.000 \\
\hline & $\mathrm{T} 24 \mathrm{~h}$ & -0.1 & 0.878 & T24 h & 1.8 & $0.023 *$ \\
\hline & $\mathrm{T72h}$ & 1.4 & 0.113 & $\mathrm{~T} 72 \mathrm{~h}$ & 3.1 & $0.027 *$ \\
\hline & v-iNPH vs p-iNPH & -3.5 & 0.237 & v-iNPH vs p-iNPH & -5.5 & 0.164 \\
\hline & double support duration & -1.6 & $0.000 * * *$ & double support duration & -1.9 & $0.000 * * *$ \\
\hline & $\mathrm{PCl}$ & -0.02 & $0.024 *$ & $\mathrm{PCl}$ & -0.1 & $0.001 * * *$ \\
\hline & n. turning steps & -2.0 & $0.000 * * *$ & & & \\
\hline \multirow[t]{7}{*}{ Cadence [strides/min] } & (Intercept) & 58.8 & 0.000 & (Intercept) & 63.3 & 0.000 \\
\hline & T24h & 1.8 & $0.009 * *$ & T24h & 1.5 & $0.000 * * *$ \\
\hline & $\mathrm{T} 72 \mathrm{~h}$ & 2.4 & $0.001 * * *$ & $\mathrm{~T} 72 \mathrm{~h}$ & 1.7 & $0.018 *$ \\
\hline & v-iNPH vs p-iNPH & -0.6 & 0.774 & v-iNPH vs p-iNPH & -0.7 & 0.654 \\
\hline & double support duration & -0.3 & $0.000 * * *$ & double support duration & -0.4 & $0.000 * * *$ \\
\hline & $\mathrm{PCl}$ & -0.01 & $0.006 * *$ & $\mathrm{PCl}$ & 0.1 & $0.000 * * *$ \\
\hline & n. turning steps & 0.4 & $0.015 *$ & & & \\
\hline \multirow[t]{9}{*}{ Total time $[\mathrm{s}]$} & (Intercept) & -10.5 & 0.000 & (Intercept) & -10.8 & 0.001 \\
\hline & $\mathrm{T} 24 \mathrm{~h}$ & -1.8 & 0.190 & T24h & -2.9 & 0.108 \\
\hline & $\mathrm{T} 72 \mathrm{~h}$ & -2.8 & $0.031 *$ & $\mathrm{~T} 72 \mathrm{~h}$ & -2.7 & 0.160 \\
\hline & v-iNPH vs p-iNPH & 0.4 & 0.677 & v-iNPH vs p-iNPH & 2.0 & 0.137 \\
\hline & double support duration & 0.6 & $0.000 * * *$ & double support duration & 1.2 & $0.000 * * *$ \\
\hline & $\mathrm{PCl}$ & 0.1 & $0.000 * * *$ & $\mathrm{PCl}$ & 0.2 & $0.000 * * *$ \\
\hline & n. turning steps & 1.7 & $0.000 * * *$ & & & \\
\hline & Sit-down duration & 0.5 & $0.000 * * *$ & & & \\
\hline & Stand-up duration & 0.5 & $0.005^{* *}$ & & & \\
\hline
\end{tabular}

T24 $h$ and $T 72 h$ post 24 and $72 h$ the CSF tap test;

$v$-iNPH vs $p$-iNPH pure iNPH group vs iNPH with vascular encephalopathy comorbidity group;

$\mathrm{PCl}$ phase coordination index;

Values of stride length are expressed in $\mathrm{cm}$, of cadence in strides/min, of total time in $\mathrm{s}$;

Significance codes: ${ }^{\prime * * * \prime} p<0.001,{ }^{\prime * * \prime} p<0.01,{ }^{\prime * \prime} p<0.05$

diagnosed as iNPH by a clinical multidisciplinary team following a standardized protocol.

Motor performance was measured using inertial sensors which allowed to instrument the TUG and the 18 $\mathrm{mW}$ tests without affecting the clinical routine. More so,
IMUs allowed to measure gait parameters such as the duration of the double support phase and the PCI that are directly related to typical disturbances of iNPH as the presence of magnetic gait and of apraxia. Cadence, stride length and total time, being three main

Table 3 Levene's Test for homogeneity of variance on residuals of statistical model of Eq. 1

\begin{tabular}{|c|c|c|c|c|c|c|}
\hline & TUG & & & $18 \mathrm{~mW}$ & & \\
\hline & $\begin{array}{l}\text { Stride length } \\
p \text {-value }\end{array}$ & $\begin{array}{l}\text { Cadence } \\
p \text {-value }\end{array}$ & $\begin{array}{l}\text { Total time } \\
p \text {-value }\end{array}$ & $\begin{array}{l}\text { Stride length } \\
p \text {-value }\end{array}$ & $\begin{array}{l}\text { Cadence } \\
p \text {-value }\end{array}$ & $\begin{array}{l}\text { Total time } \\
p \text {-value }\end{array}$ \\
\hline i & $0.001^{* * *}$ & $0.000^{* * *}$ & $0.000^{* * *}$ & $0.002^{* *}$ & $0.003^{* *}$ & $0.001^{* * *}$ \\
\hline$t$ & 0.913 & 0.374 & 0.835 & $0.016^{*}$ & 0.536 & $0.049^{*}$ \\
\hline$i^{*} \mathrm{t}$ & 0.999 & 0.400 & $0.017^{*}$ & 0.993 & 0.829 & 0.787 \\
\hline
\end{tabular}

$i$ variability among subjects;

$t$ variability among time points baseline, $\mathrm{T} 24 \mathrm{~h}$ and $\mathrm{T} 72 \mathrm{~h}$;

$i^{*} t$ : variability among subjects and time points;

Significance codes: ${ }^{1 * * * \prime} p<0.001{ }^{\prime * * \prime} p<0.011^{\prime * \prime} p<0.05$ 
Table 4 Mean scores of clinical scales

\begin{tabular}{|c|c|c|c|c|}
\hline \multirow[b]{2}{*}{ Mean scores } & \multicolumn{2}{|l|}{$\mathrm{p}$-iNPH } & \multicolumn{2}{|l|}{$\mathrm{v-iNPH}$} \\
\hline & Baseline & $\mathrm{T72h}$ & Baseline & $\mathrm{T72h}$ \\
\hline Gait Status Scale (st. Dev) [subjects] & $5.5(3.8)[54]$ & $4.3(3.5)[53]$ & $6.4(3.3)[19]$ & $4.3(2.7)[18]$ \\
\hline Tinetti Balance & $12.0(3.7)[54]$ & $13.8(2.5)[52]$ & $11.7(2.9)[19]$ & $13.1(2.6)[18]$ \\
\hline Tinetti Gait & $7.0(3.4)[54]$ & $8.8(2.6)[52]$ & $6.8(3.0)[19]$ & $8.6(2.5)[18]$ \\
\hline Tinetti & $18.9(6.6)[54]$ & $22.4(4.7)[52]$ & $18.6(5.4)[19]$ & $21.7(4.6)[18]$ \\
\hline Grading Scale & $5.9(2.4)[56]$ & $4.5(2.1)[53]$ & $5.9(2.3)[19]$ & $5.2(2.7)[18]$ \\
\hline
\end{tabular}

st. Dev standard deviation;

[subjects]: number of subjects able to execute the tasks of the clinical scale;

$T 72 \mathrm{~h}$ post $72 \mathrm{~h}$ the CSF tap test;

$p$-iNPH pure iNPH group;

$v$-iNPH iNPH with vascular encephalopathy comorbidity group

complimentary components of locomotion, were selected as response variables of statistical models implemented to assess modifications caused by CSF-TT, hence to establish and quantify its effect on symptoms improvement. The choice to use a $18 \mathrm{~mW}$ allowed the stress the locomotor abilities of patients, but the use of the more standard $10 \mathrm{~mW}$ would have allowed a broader opportunity of comparisons with the literature and in future studies might be preferred.

Comparing gait analysis results obtained in the TUG test at baseline and post-CSF-TT, on average, as showed in Fig. 3a, patients increased their cadence and reduced the time required to complete the test (Table 2). Conversely, stride length did not change, probably due to the

Table 5 Results of the statistical analysis on the outcome measures stride length, cadence and total time considering as predictors both the instrumental gait analysis parameters and the scores of clinical scales (model defined in Eq. 2)

\begin{tabular}{|c|c|c|c|c|c|c|}
\hline & \multicolumn{3}{|l|}{ TUG } & \multicolumn{3}{|l|}{$18 \mathrm{~mW}$} \\
\hline & & Value & $p$-value & & Value & $\overline{p \text {-value }}$ \\
\hline \multirow[t]{8}{*}{ Stride length [cm] } & (Intercept) & 135.4 & 0.000 & (Intercept) & 164.3 & 0.000 \\
\hline & $\mathrm{T} 72 \mathrm{~h}$ & -1.9 & 0.064 & $\mathrm{~T} 72 \mathrm{~h}$ & 2.9 & 0.071 \\
\hline & v-iNPH vs p-iNPH & -2.0 & 0.414 & v-iNPH vs p-iNPH & -3.1 & 0.307 \\
\hline & double support duration & -1.6 & $0.000 * * *$ & double support duration & -1.9 & $0.000 * * *$ \\
\hline & n. turning steps & -2.9 & $0.000 * * *$ & $\mathrm{PCl}$ & -0.1 & $0.035 *$ \\
\hline & Tinetti Gait & 1.2 & $0.004 * *$ & Tinetti Gait & 2.8 & $0.000 * * *$ \\
\hline & Gait Status Scale & -1.0 & $0.010 * *$ & Gait Status Scale & -2.0 & $0.004 *$ \\
\hline & & & & Tinetti Balance & -1.6 & $0.043 *$ \\
\hline \multirow[t]{6}{*}{ Cadence [strides/min] } & (Intercept) & 59.5 & 0.000 & (Intercept) & 63.4 & 0.000 \\
\hline & $\mathrm{T} 72 \mathrm{~h}$ & 3.0 & $0.000^{* * *}$ & $\mathrm{~T} 72 \mathrm{~h}$ & 1.6 & 0.070 \\
\hline & v-iNPH vs p-iNPH & -0.9 & 0.670 & v-iNPH vs p-iNPH & 0.1 & 0.944 \\
\hline & double support duration & -0.4 & $0.000 * * *$ & double support duration & -0.4 & $0.000 * * *$ \\
\hline & n. turning steps & 0.7 & $0.002 * *$ & $\mathrm{PCl}$ & 0.1 & $0.001 * * *$ \\
\hline & Gait Status Scale & 0.6 & $0.004^{* *}$ & & & \\
\hline \multirow[t]{7}{*}{ Total time $[\mathrm{s}]$} & (Intercept) & 2.5 & 0.549 & (Intercept) & 13.9 & 0.032 \\
\hline & $\mathrm{T} 72 \mathrm{~h}$ & -1.6 & 0.156 & $\mathrm{~T} 72 \mathrm{~h}$ & -1.7 & 0.446 \\
\hline & v-iNPH vs p-iNPH & 0.3 & 0.757 & v-iNPH vs p-iNPH & 1.2 & 0.482 \\
\hline & double support duration & 0.7 & $0.000 * * *$ & double support duration & 0.8 & $0.000 * * *$ \\
\hline & $\mathrm{PCl}$ & 0.03 & $0.000 * * *$ & $\mathrm{PCl}$ & 0.2 & $0.000 * * *$ \\
\hline & Sit-down duration & 0.6 & $0.000 * * *$ & Tinetti Gait & -1.4 & $0.001 * * *$ \\
\hline & Tinetti Balance & -0.9 & $0.000 * * *$ & & & \\
\hline
\end{tabular}

T72 $\mathrm{h}$ post $72 \mathrm{~h}$ the CSF tap test;

$v$-iNPH vs $p$-iNPH pure iNPH group vs iNPH with vascular encephalopathy comorbidity group $\mathrm{PCl}$ phase coordination index

Significance codes: ${ }^{* * * \prime} p<0.001,{ }^{* * \prime} p<0.01,{ }^{* *} p<0.05$ 
Table 6 Levene's Test for homogeneity of variance on residuals of statistical model of Eq. 2

\begin{tabular}{|c|c|c|c|c|c|c|}
\hline \multirow{3}{*}{ 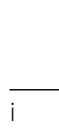 } & \multicolumn{3}{|l|}{ TUG } & \multicolumn{3}{|l|}{$18 \mathrm{~mW}$} \\
\hline & Stride Length & Cadence & Total time & Stride Length & Cadence & Total time \\
\hline & $0.000^{* * *}$ & $0.000^{* * *}$ & $0.000^{* * *}$ & 0.344 & 0.341 & 0.141 \\
\hline t & 0.847 & 0.592 & 0.538 & $0.008^{* *}$ & 0.495 & $0.013^{*}$ \\
\hline$i^{*} t$ & 0.989 & 0.146 & $0.001^{* * *}$ & 0.882 & 0.771 & 0.733 \\
\hline
\end{tabular}

$i$ i-th subject

$t$ time point: baseline, $\mathrm{T} 24 \mathrm{~h}$ or $\mathrm{T} 72 \mathrm{~h}$

Significance codes: ${ }^{* * * \prime} p<0.001,{ }^{\prime * * \prime} p<0.01,{ }^{\star * \prime} p<0.05$

nature of TUG that limits free walking to just $3 \mathrm{~m}$. On the other hand, in the $18 \mathrm{~mW}$ test stride length and cadence significantly improved, whereas the change in total time, even showing a reduction of more than $2 \mathrm{~s}$ on average (Fig. 3b, Table 2), did not reach statistical significance. This latter result might be partially explained by the fact that at $T 72 \mathrm{~h}$ just 15 patients performed the $18 \mathrm{~mW}$ causing a reduced statistical power compared to TUG. More so, this might suggest that the performance of iNPH patients is subject to modifications not necessarily involving gross motor skills, but aspects related to the quality of motor control such as the onset of apraxia.
In line with this interpretation, double support duration and PCI were the two regressors most influent for explaining total time revealing how moving from baseline to T72 $\mathrm{h}$ patients exhibited a gait less magnetic and apraxic, and more coordinated and fluent.

Considering clinical scores analyzed in addition to instrumental measures as in Eq. 2 (results in Table 5), from baseline to $\mathrm{T} 72 \mathrm{~h}$ patients increased their cadence significantly in TUG. As well, concerning clinical scores analyzed by themselves as in Eq. 3 (results Table 7), the cadence is increased both in TUG and $18 \mathrm{~mW}$. Time effect in the explanation of the variability of performance

Table 7 Results of the statistical analysis on the outcome measures stride length, cadence and total time considering the scores of clinical scales as the only predictors (model defined in Eq. 3)

\begin{tabular}{|c|c|c|c|c|c|c|}
\hline & \multicolumn{3}{|l|}{ TUG } & \multicolumn{3}{|l|}{$18 \mathrm{~mW}$} \\
\hline & & Value & $p$-value & & Value & $p$-value \\
\hline \multirow[t]{7}{*}{ Stride length $[\mathrm{cm}]$} & (Intercept) & 46.9 & 0.000 & (Intercept) & 85.6 & 0.000 \\
\hline & $\mathrm{T} 72 \mathrm{~h}$ & -2.3 & 0.206 & $\mathrm{~T} 72 \mathrm{~h}$ & 4.0 & 0.130 \\
\hline & Tinetti Gait & 2.4 & 0.209 & Tinetti Gait & 5.9 & $0.002^{* *}$ \\
\hline & Tinetti Balance & 1.0 & 0.583 & Tinetti Balance & -1.6 & 0.392 \\
\hline & Tinetti & 0.2 & 0.902 & Tinetti & -0.4 & 0.808 \\
\hline & Gait Status Scale & -1.7 & $0.013^{*}$ & Gait Status Scale & -2.3 & $0.022^{*}$ \\
\hline & Grading Scale & -1.4 & 0.060 & Grading Scale & -0.7 & 0.471 \\
\hline \multirow[t]{7}{*}{ Cadence [strides/min] } & (Intercept) & 51.7 & 0.000 & (Intercept) & 61.0 & 0.000 \\
\hline & $\mathrm{T} 72 \mathrm{~h}$ & 2.8 & $0.002^{* *}$ & $\mathrm{~T} 72 \mathrm{~h}$ & 2.5 & $0.023^{*}$ \\
\hline & Tinetti Gait & -0.3 & 0.733 & Tinetti Gait & -0.2 & 0.838 \\
\hline & Tinetti Balance & 0.3 & 0.702 & Tinetti Balance & -0.2 & 0.825 \\
\hline & Tinetti & -0.1 & 0.883 & Tinetti & -0.1 & 0.845 \\
\hline & Gait Status Scale & 0.4 & 0.231 & Gait Status Scale & -0.5 & 0.247 \\
\hline & Grading Scale & -0.9 & $0.021^{*}$ & Grading Scale & -0.4 & 0.398 \\
\hline \multirow[t]{7}{*}{ Total time $[\mathrm{s}]$} & (Intercept) & 30.0 & 0.000 & (Intercept) & 38.7 & 0.006 \\
\hline & $\mathrm{T} 72 \mathrm{~h}$ & -1.6 & 0.248 & $\mathrm{~T} 72 \mathrm{~h}$ & -2.7 & 0.338 \\
\hline & Tinetti Gait & 0.01 & 0.988 & Tinetti Gait & -2.2 & 0.096 \\
\hline & Tinetti Balance & -0.6 & 0.482 & Tinetti Balance & 1.1 & 0.338 \\
\hline & Tinetti & -0.3 & 0.670 & Tinetti & -0.5 & 0.598 \\
\hline & Gait Status Scale & 0.5 & 0.156 & Gait Status Scale & 0.6 & 0.391 \\
\hline & Grading Scale & 0.8 & $0.013^{*}$ & Grading Scale & 0.8 & 0.359 \\
\hline
\end{tabular}


measures is therefore attenuated by the addition of clinical scores to statistical models. When looking at the individual contribution of each scale, there was not a single scale fitting well in all statistical models. Tinetti Gait and Gait Status Scale were both explanatory variables in prediction of stride length both for TUG and $18 \mathrm{~mW}$ in the model including quantitative measures (Table 5), but only for 18 $\mathrm{mW}$ in the model with clinical scales alone (Table 7), revealing their ability to address stride length variations besides instrumental data. Tinetti Gait was the only scale remaining significant in explaining the variability of total time for $18 \mathrm{~mW}$ (Table 5), hence showing its affinity to gait speed during an unconstrained walk. Tinetti Balance, along with gait analysis data, Tinetti Gait and Gait Status Scale were significant for predicting stride length in 18 $\mathrm{mW}$ (Table 5). More so, Tinetti Balance was the only scale predictive of TUG total time (Table 5), probably reflecting its ability to address those components of motor organization related to the pattern adopted to find and maintain balance during the sit-to-stand and stand-to-sit postural transfers. For TUG, in the model including instrumental data, to a unitary increment of Gait Status Scale, theoretically corresponding to a worsening of patients' motor abilities, corresponded a significant increase of cadence of $0.6 \mathrm{steps} / \mathrm{min}$ as well as a $1 \mathrm{~cm}$ reduction of stride length, on average. These results, though partially controversial, probably reveal the presence of shuffling gait for patients with higher values of Gait Status Scale. In other words, with the increase of values of Gait Status Scale the performance deteriorates in terms of reduced stride length and, counterintuitively, increased cadence, which clinically can be associated to the presence of a shuffling gait.

Tinetti Gait, Tinetti Balance and Gait Status Scale in TUG provided a contribution more relevant with respect to stand-up time and turning steps in total time, and to PCI in stride length and cadence. This result can be probably ascribed to their capability of assessing a broad spectrum of top-down components of the motor repertoire necessary to execute the TUG. On the contrary, Tinetti global score and Grading Scale when analyzed with instrumental data were never selected for model fitting, revealing their inability to unveil undisclosed aspects of performance. Overall, the fact that some clinical scales in the statistical model of Eq. 2 provided a contribution more relevant with respect to gait analysis parameters also suggests that other instrumental data, obtained from inertial sensors or other devices, might be considered in order to fully describe pre vs post-CSF-TT modifications of motor performance just in terms of objective data.

Grading Scale on the other hand, in the model with clinical scales alone, was the only scale found significant for cadence and total time in TUG, demonstrating its ability to explain the majority of the variability of these two outcome measures to the detriment of other clinical scales.

When analysing the variance of statistical model residuals relative to the interaction between time and subjects, the homoscedasticity is always present except for the total time in TUG (Table 3 and Table 6). This latter finding possibly indicates that a factor relevant for the determination of the parameter total time has not been taken into account into the statistical model. Based on clinical observations, this factor might have been the cognitive ability to correctly implement the test without hesitations, that was frequently compromised at baseline but often recovered at $\mathrm{T} 72 \mathrm{~h}$. Indeed, patients at baseline sometimes got lost during test execution, for example continuing to walk straight instead of turning and returning to the chair. In these cases, the TUG was disclosing not only the locomotor abilities but also the cognitive functioning of patients. By inserting the scores of a scale such as the Mini Mental State Examination [39] in the statistical model of total time as a fixed effect, could effectively account for the presence and severity of cognitive impairment and its role in the variation of the motor performance. Further research aimed at confirming this hypothesis should be carried out.

$\mathrm{v}$-iNPH patients showed on average a reduced performance compared to $\mathrm{p}$-iNPH in all the different observations but without reaching the statistical significance. Contrary to authors expectations, important vascular encephalopathy present in persons with $\mathrm{v}$-iNPH was not a factor causing a different post-CSF-TT course. This result might be partially explained by the fact that the high individual variability modeled with the random intercept captured only part of the variability ascribed to the two iNPH groups. On the other hand, this result suggests that vascular encephalopathy is not a comorbidity limiting the improvement of gait following CSF-TT. In the present study, the ARWMC was dichotomized in order to ease the clinical interpretation of the results. However, including this variable into the statistical models themselves as fixed effect might increase the variance explained and turn out to be a significant predictor of the responsive variables.

When comparing different post-CSF-TT assessment times, the better performances were recorded $72 \mathrm{~h}$ after the CSF-TT. This finding is clearly visible in the radar plots of Fig. 2 where the hexagon relative to median values of spatio-temporal gait parameters recorder at $\mathrm{T} 72 \mathrm{~h}$ is always including, meaning better performance, the one relative to $T 24 \mathrm{~h}$. These results are in agreement with those reported by Schniepp et al. but in contrast to other studies $[10,22]$, and in particular with the work of Virhammar et al. that proposed to make the post-CSFTT evaluation any time within the first $24 \mathrm{~h}$ [12]. These 
findings also suggest that previous studies investigating motor improvements in early time points could have underestimated the CSF-TT response.

\section{Conclusions}

Inertial sensors used to instrument motor tests on iNPH patients allowed to assess changes on performances due to CSF-TT without affecting the clinical routine and unveiling aspects of locomotion and postural transfers not accessible simply using clinical observations or clinical scales. On average, patients improved the performance from baseline to post-CSF-TT particularly increasing cadence in $18 \mathrm{~mW}$ and TUG and stride length in $18 \mathrm{~mW}$. More so, the use of data from inertial sensors and mixed effects models allowed to show how the improvement was significant especially in those gait parameters reflecting a decrease in apraxia such as the reduction of double support duration and the increase of coordination.

Tinetti Gait, Tinetti Balance and Gait Status Scale were the scales able, better than others, to address part of the variability of response variables not explained by sensor data. Additionally, these scales in TUG provided a contribution more relevant with respect to stand-up time and turning steps in total time, and to $\mathrm{PCI}$ in stride length and cadence, showing the capability to assess components of the motor repertoire not appropriately addressed by gait parameters. On the other hand, when considering clinical scales alone, Grading Scale was the scale with highest affinity in explaining TUG total time and cadence.

$\mathrm{v}$-iNPH patients compared to $\mathrm{p}$-iNPH showed worst performances in all evaluations but without reaching statistical significance. This comorbidity was not a factor causing a different post-CSF-TT course by limiting gait improvement.

Maximal increase in outcome measures occurred the third day after the CSF-TT, revealing how this interval should be the considered as the best spot to assess CSFTT efficacy in iNPH.

In conclusion, the results obtained in this study suggest that it is possible to improve the assessment of effectiveness of the CSF-TT by including the instrumented evaluation of spatio-temporal gait parameters and setting the time for post-CSF-TT evaluation at $72 \mathrm{~h}$.

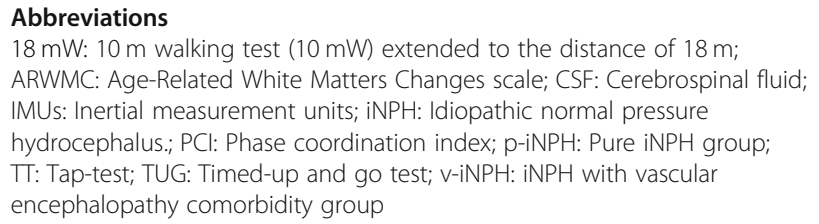

$18 \mathrm{~mW}: 10 \mathrm{~m}$ walking test $(10 \mathrm{~mW}$ ) extended to the distance of $18 \mathrm{~m}$; ARWMC: Age-Related White Matters Changes scale; CSF: Cerebrospinal fluid; IMUs: Inertial measurement units; iNPH: Idiopathic normal pressure hydrocephalus.; PCl: Phase coordination index; p-iNPH: Pure iNPH group; TT: Tap-test; TUG: Timed-up and go test; v-iNPH: iNPH with vascular encephalopathy comorbidity group

\section{Acknowledgements}

The authors would like to thank Dr. Stefania Magnoni and Dr. Silvia Muscari for or their help in collecting and analyzing the data during their Master thesis.
Suppliers

a. mHealth Technologies.

b. MATLAB; MathWorks.

c. R; https://www.r-project.org/

\section{Authors' contributions}

Conceptualization: GP, PC and LC. Data Curation: SC and GG. Data Acquisition: DM and GG. Data Interpretation: DM, GG, GP, FO, LAR, PM, SC, AF and LC. Data Processing: AF. Statistical Analysis: LA. Original Draft Preparation: AF. Review \& Editing: LC, AF. All authors read and approved the final manuscript.

\section{Funding}

This research was conducted with internal institutional funds of University of Bologna and the IRCCS Istituto delle Scienze Neurologiche of Bologna.

\section{Availability of data and materials \\ Please contact corresponding author.}

\section{Ethics approval and consent to participate}

Subjects provided written informed consent prior to participation to the study according to the declaration of Helsinki. Ethical approval was provided by the ethics committee of the health service of Bologna reference CE 14131 $23 / 02 / 2015$, and was conducted in agreement with principles of good clinical practice.

\section{Consent for publication}

All participants gave written informed consent.

\section{Competing interests}

Two of the authors are founders of mHealth Technologies s.r.l., the company that manufactures and sells systems that are similar to the one used in this study.

\section{Author details}

${ }^{1}$ Health Sciences and Technologies - Interdepartmental Center for Industrial Research (CIRI-SDV), Alma Mater Studiorum - University of Bologna, Bologna, Italy. ${ }^{2}$ Unit of Rehabilitation Medicine, IRCCS Istituto delle Scienze Neurologiche di Bologna, Bologna, Italy. ${ }^{3}$ Unit of Neurology, IRCCS Istituto delle Scienze Neurologiche di Bologna, Bologna, Italy. ${ }^{4}$ Department of Biomedical and Neuromotor Sciences (DIBINEM), University of Bologna, Bologna, Italy. ${ }^{5}$ Unit of Neurosurgery, IRCCS Istituto delle Scienze Neurologiche di Bologna, Bologna, Italy. ${ }^{6}$ Unit of Neuroradiology, IRCCS Istituto delle Scienze Neurologiche di Bologna, Bologna, Italy. ${ }^{7}$ Department of Statistical Sciences, University of Bologna, Bologna, Italy. ${ }^{8}$ Department of Electrical, Electronic, and Information Engineering "Guglielmo Marconi" (DEI), University of Bologna, Bologna, Italy.

Received: 17 April 2019 Accepted: 22 December 2019

Published online: 16 January 2020

\section{References}

1. Hakim S, Adams RD. The special clinical problem of symptomatic hydrocephalus with normal cerebrospinal fluid pressure. Observations on cerebrospinal fluid hydrodynamics. J Neurol Sci. 1965;2:307-27.

2. Gallia GL, Rigamonti D, Williams MA. The diagnosis and treatment of idiopathic normal pressure hydrocephalus. Nat Clin Pract Neurol. 2006;2(7): 375-81.

3. Toma AK, Papadopoulos MC, Stapleton S, Kitchen ND, Watkins LD. Systematic review of the outcome of shunt surgery in idiopathic normalpressure hydrocephalus. Acta Neurochir (Wien). 2013;155(10):1977-80.

4. Relktin N, Marmarou A, Klinge P, Bergsneider M, Black PML. INPH guidelines, part II: diagnosing idio-pathic normal-pressure hydrocephalus. Neurosurgery. 2005;57:4-16.

5. Marmarou A, Bergsneider M, Relkin N, Klinge P, Black PM. Development of Guidelines for Idiopathic Normal-pressure Hydrocephalus: Introduction. Neurosurgery. 2005:57:S2-1-S2-3.

6. Mori E, Ishikawa M, Kato T, Kazui H, Miyake H, Miyajima M, et al. Guidelines for management of idiopathic normal pressure hydrocephalus: second edition. Neurol Med Chir (Tokyo). 2012;52:775-809. 
7. Agostini V, Lanotte M, Carlone M, Campagnoli M, Azzolin I, Scarafia R, et al. Instrumented gait analysis for an objective pre-/postassessment of tap test in normal pressure hydrocephalus. Arch Phys Med Rehabil. 2015:96:1235-41.

8. Liston R, Mickelborough J, Bene J, Tallis R. A new classification of higher level gait disorders in patients with cerebral multi-infarct states. Age Ageing. 2003;32:252-8

9. Marmarou A, Bergsneider M, Klinge P, Relkin N, Black PM. The value of supplemental prognostic tests for the preoperative assessment of idiopathic normal-pressure hydrocephalus. Neurosurgery. 2005;57:S17-28 discussion ii-v.

10. Mihalj M, Dolić K, Kolić K, Ledenko V. CSF tap test - obsolete or appropriate test for predicting shunt responsiveness? A systemic review. J Neurol Sci. 2016;362:78-84.

11. Ravdin LD, Katzen HL, Jackson AE, Tsakanikas D, Assuras S, Relkin NR. Features of gait most responsive to tap test in normal pressure hydrocephalus. Clin Neurol Neurosurg. 2008;110:455-61.

12. Virhammar J, Cesarini KG, Laurell K. The CSF tap test in normal pressure hydrocephalus: evaluation time, reliability and the influence of pain. Eur J Neurol. 2012;19:271-6.

13. Kubo $Y$, Kazui $H$, Yoshida $T$, Kito $Y$, Kimura $N$, Tokunaga $H$, et al. Validation of grading scale for evaluating symptoms of idiopathic normal-pressure hydrocephalus. Dement Geriatr Cogn Disord. 2007;25:37-45.

14. Muro-de-la-Herran A, García-Zapirain B, Méndez-Zorrilla A. Gait analysis methods: an overview of wearable and non-wearable systems, highlighting clinical applications. Sensors (Switzerland). 2014;14:3362-94.

15. Ferrari A, Ginis P, Hardegger M, Casamassima F, Rocchi L, Chiari L. A Mobile Kalman-filter based solution for the real-time estimation of Spatio-temporal gait parameters. IEEE Trans Neural Syst Rehabil Eng. 2016;24:764-73.

16. Yang F, Hickman T-T, Tinl M, Iracheta C, Chen G, Flynn P, et al. Quantitative evaluation of changes in gait after extended cerebrospinal fluid drainage for normal pressure hydrocephalus. J Clin Neurosci. 2016; 28:31-7.

17. Stolze H, Kuhtz-Buschbeck JP, Drücke $H$, Jöhnk K, Diercks C, Palmié S, et al. Gait analysis in idiopathic normal pressure hydrocephalus - which parameters respond to the CSF tap test? Clin Neurophysiol. 2000;111:1678-86.

18. Panciani PP, Migliorati K, Muratori A, Gelmini M, Padovani A, Fontanella M. Computerized gait analysis with inertial sensor in the management of idiopathic normal pressure hydrocephalus. Eur J Phys Rehabil Med. 2018;54:724-9.

19. Bovonsunthonchai $S$, Witthiwej T, Ngamsombat C, Sathornsumetee $S$, Vachalathiti R, Muangpaisan W, et al. Effect of spinal tap test on the performance of sit-to-stand, walking, and turning in patients with idiopathic normal pressure hydrocephalus. Nagoya J Med Sci. 2018;80:53-60.

20. Allali G, Laidet M, Armand S, Momjian S, Marques B, Saj A, et al. A combined cognitive and gait quantification to identify normal pressure hydrocephalus from its mimics: the Geneva's protocol. Clin Neurol Neurosurg. 2017;160:5-11

21. Tinetti ME, Franklin Williams T, Mayewski R. Fall risk index for elderly patients based on number of chronic disabilities. Am J Med. 1986;80:429-34.

22. Gallagher R, Marquez J, Osmotherly P. Gait and balance measures can identify change from a cerebrospinal fluid tap test in idiopathic Normal pressure hydrocephalus. Arch Phys Med Rehabil. 2018;99:2244-50.

23. Allali G, Laidet M, Beauchet O, Herrmann FR, Assal F, Armand S. Dual-task related gait changes after CSF tapping: a new way to identify idiopathic normal pressure hydrocephalus. J Neuroeng Rehabil. 2013;10:1-6.

24. Armand S, Allet L, Landis T, Beauchet O, Assal F, Allali G. Interest of dualtask-related gait changes in idiopathic normal pressure hydrocephalus. Eur J Neurol. 2011;18:1081-4.

25. Schniepp R, Trabold R, Romagna A, Akrami F, Hesselbarth K, Wuehr M, et al. Walking assessment after lumbar puncture in normal-pressure hydrocephalus: a delayed improvement over 3 days. J Neurosurg. 2017; 126:148-57

26. Giannini G, Palandri G, Ferrari A, Oppi F, Milletti D, Albini-Riccioli L, et al. A prospective evaluation of clinical and instrumental features before and after ventriculo-peritoneal shunt in patients with idiopathic Normal pressure hydrocephalus: the Bologna PRO-hydro study. Parkinsonism Relat Disord England. 2019:66:117-24.

27. Wahlund LO, Barkhof F, Fazekas F, Bronge L, Augustin M, Sjögren M, et al. A new rating scale for age-related white matter changes. Stroke. 2001;32: $1318-22$.
28. Mendes GAS, de Oliveira MF, Pinto FCG. The timed up and go test as a diagnostic criterion in Normal pressure hydrocephalus. World Neurosurg Elsevier Inc. 2017;105:456-61.

29. Kahlon B, Sundbärg G, Rehncrona S. Comparison between the lumbar infusion and CSF tap tests to predict outcome after shunt surgery in suspected normal pressure hydrocephalus. J Neurol Neurosurg Psychiatry. 2002;73:721-6.

30. Casamassima F, Ferrari A, Milosevic B, Ginis P, Farella E, Rocchi L. A wearable system for gait training in subjects with Parkinson's disease. Sensors (Basel). 2014;14:6229-46.

31. Plotnik M, Giladi N, Hausdorff JM. A new measure for quantifying the bilateral coordination of human gait: effects of aging and Parkinson's disease. Exp Brain Res. 2007;181:561-70.

32. Palmerini L, Mellone S, Avanzolini G, Valzania F, Chiari L. Quantification of motor impairment in Parkinson's disease using an instrumented timed up and go test. IEEE Trans Neural Syst Rehabil Eng. 2013;21:664-73.

33. Hollman JH, McDade EM, Petersen RC. Normative spatiotemporal gait parameters in older adults. Gait Posture. 2011;34:111-8.

34. Gueorguieva R, Krystal JH. Move Over ANOVA. Arch Gen Psychiatry. 2004:61:310-7.

35. Prescott RJ. Avoid being tripped up by statistics: statistical guidance for a successful research paper. Gait Posture. 2019:72:240-9.

36. Stewart S, Pearson J, Rome K, Dalbeth N, Vandal AC. Analysis of data collected from right and left limbs: accounting for dependence and improving statistical efficiency in musculoskeletal research. Gait Posture. 2018:59:182-7.

37. Gałecki A, Burzykowski T. Linear Mixed-Effects Models Using R. New York: Springer; 2013.

38. Bonnyaud C, Pradon D, Vaugier I, Vuillerme N, Bensmail D, Roche N. Timed Up and Go test: Comparison of kinematics between patients with chronic stroke and healthy subjects. Gait Posture. 2016;49:258-63.

39. Folstein MF, Folstein SE, McHugh PR. "Mini-mental state": a practical method for grading the cognitive state of patients for the clinician. J Psychiatr Res. 1975;12:189-98

\section{Publisher's Note}

Springer Nature remains neutral with regard to jurisdictional claims in published maps and institutional affiliations.
Ready to submit your research? Choose BMC and benefit from:

- fast, convenient online submission

- thorough peer review by experienced researchers in your field

- rapid publication on acceptance

- support for research data, including large and complex data types

- gold Open Access which fosters wider collaboration and increased citations

- maximum visibility for your research: over $100 \mathrm{M}$ website views per year

At BMC, research is always in progress.

Learn more biomedcentral.com/submissions 